\title{
The workbook "Adaptation in the labor market": development and use in training bachelor students
}

\author{
M. V. Shalaeva ${ }^{1, *}$ \\ ${ }^{1}$ Industrial University of Tyumen, Branch in Nizhnevartovsk, 2P/9, Lenin av., 628616, Nizhnevartovsk, Russia
}

\begin{abstract}
The experience of development and use of the workbook "Adaptation in the labor market" as a mechanism to increase the effectiveness of independent work of bachelor students is described. The workbook used for extracurricular and classroom activities allows students to form required competencies, individualizes and differentiates the learning process, motivates the self-development and self-education, develops reflection skills and creative abilities. As a result of mastering the discipline "Adaptation in the labor market" using the workbook, students develop clearer ideas about requirements of the modern labor market, professional environment, the need for continuous self-development and self-education, which positively affects their readiness for professional activities and labor functions that meet the requirements of a modern employer.
\end{abstract}

\section{Introduction}

The innovative orientation of modern Russian society actualizes the need for competent and competitive specialists who are able to use a large flow of information and make responsible decisions aimed at continuous selfdevelopment and self-education, ready for social and professional changes, quick response to them. The education system has a special responsibility to satisfy this social need. Today, modernization of higher education is carried out through the development and implementation of new federal state educational standards in which individualization of education and creation of optimal conditions for the development of the creative potential of future specialists are the most important areas. Moreover, it is necessary to increase the share of independent activities, which requires teachers possessing effective didactic tools and new forms of interaction with students.

\section{Materials and methods}

Currently, the main issues that the university is facing are: the development of students' competitiveness and the formation of their competitive ability in the labor market [1]. Student competitiveness is defined as "a special type of economic thinking aimed at ensuring constant selfdevelopment, advancement and success in the global world in all its situations, and mastering relevant technologies and methods" [2]. The university, the employer, and parents (close relatives) are involved in the student's competitive orientation process. Competitiveness of an individual precedes the formation of his or her competitive ability.

Moreover, the system of interaction between universities and employers at the present time as a whole remains ineffective. In particular, the results of opinion polls testify to this, reflecting the inconsistency of a number of mutual expectations of university graduates and employers. Among the most massive surveys is a survey conducted in 2015 by the research center of one of the popular portals for job search and headhunting (Superjob). It was attended by 2,600 citizens of the Russian Federation: 1,000 HR managers and 1,600 university students/graduates aged 20 to 25 [3].

Obvious differences in mutual expectations are noted, on the one hand, in the orientation of young people to the need for employment history and a prestigious university diploma to a greater extent than that is required by the employer and their underestimation of such important qualities for the employer as motivation, willingness to learn, and an active life position, as well as the general level of education and culture (Fig. 1). On the other hand, employers themselves tend to underestimate such significant for young people factors as the psychological climate and comfortable working conditions, believing that university graduates in employment should, first of all, be focused on the company's image and interested in the possibility of corporate training (Fig. 2).

\footnotetext{
* Corresponding author: rina78.86@mail.ru
} 


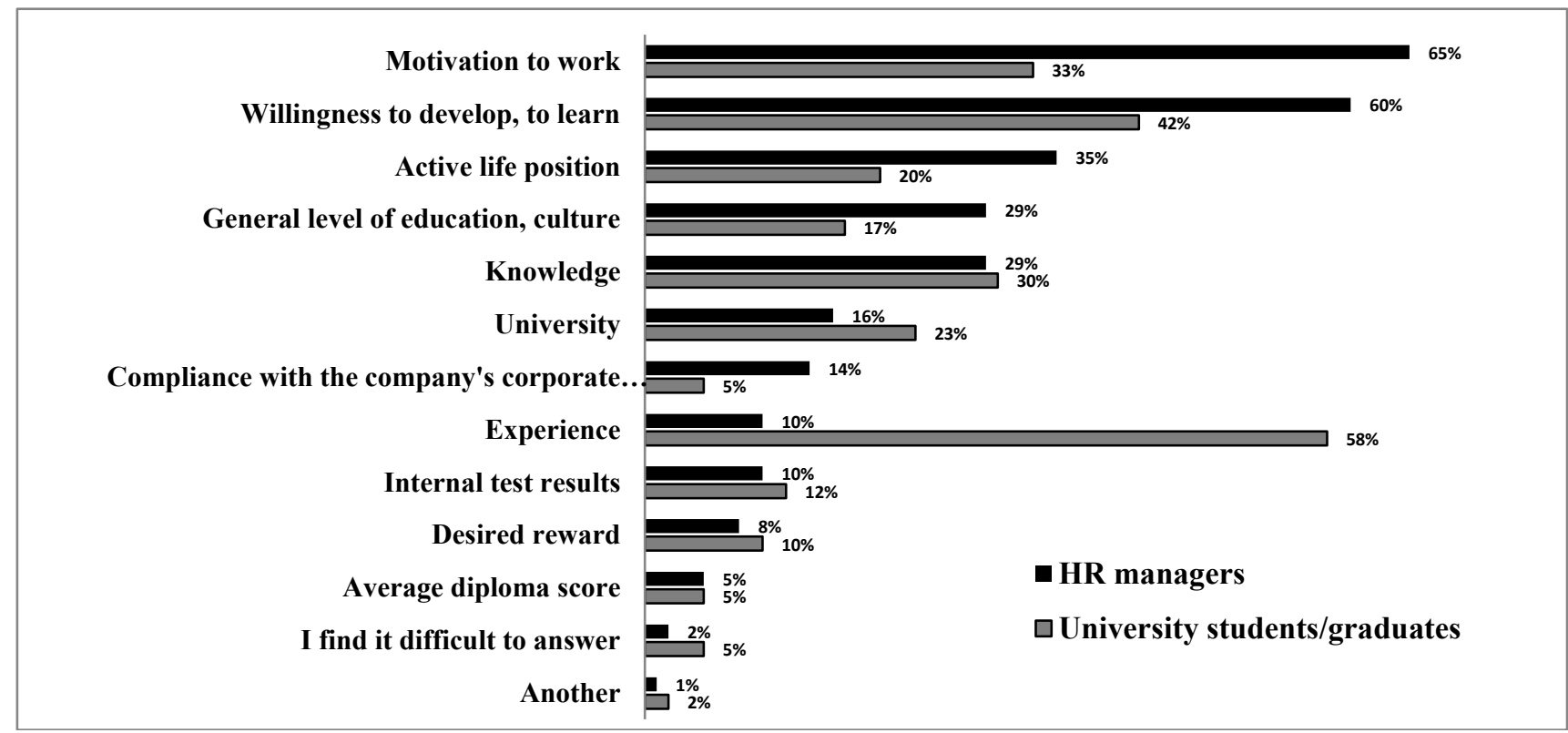

Fig. 1. Correlation of employers' expectations from university graduates and perceptions of students/university graduates about employer expectations

\begin{tabular}{|c|c|}
\hline Career prospects & $\begin{array}{ll} & \\
& 53 \%\end{array}$ \\
\hline High pay & $\begin{array}{ll} & 33 \% \\
\end{array}$ \\
\hline Personal growth prospects & $\begin{array}{ll} & 22 \% \\
\end{array}$ \\
\hline Opportunities for corporate training & $\begin{array}{ll} & 27 \% \\
\end{array}$ \\
\hline Stability/sustainability of the company & $25 \%$ \\
\hline Interesting tasks & \begin{tabular}{|l|l} 
& $24 \%$ \\
\end{tabular} \\
\hline Company image/reputation & $22 \%$ \\
\hline Comfortable psychological atmosphere & $20 \%$ \\
\hline Adequacy of superiors & $12 \%$ \\
\hline Convenient location & $21 \%$ \\
\hline Worthy compensation package & ${ }_{5 \%} 7 \%$ \\
\hline Corporate culture & $\square_{2 \%} \% \%$ \\
\hline Efficiency of management systems & HR manaoers \\
\hline Maintaining a life balance & ${ }^{3 \%} \%$ \\
\hline I find it difficult to answer & $\begin{array}{l}\square \text { University } \\
\text { students/graduates }\end{array}$ \\
\hline Another & $\begin{array}{ll}1 \% \\
1 \%\end{array}$ \\
\hline
\end{tabular}

Fig. 2. Correlation of the expectations of students/graduates from employers and the perceptions of employers about the expectations of students/graduates

It is obvious that the younger generation relies on external indicators of success in the struggle for their own "survival" in the labor market - the status of a university providing professional education; working experience; high salary; company stability; convenient location; adequacy of superiors, etc. - while it is required to focus on the development of personal qualities, aimed at continuous personal and professional growth: motivation to work and readiness for continuous development and training.

Thus, in its educational paradigm, a modern university, responding to the socio-economic trends of the time, must necessarily take into account the fact that professional education will contribute to the formation of a competitive personality only if the training process is carried out in close cooperation with a potential employer. 
One of the first steps towards creating conditions conducive to the formation and development of competitive qualities among students of the Tyumen Industrial University (TIU) was the introduction of the discipline "Adaptation in the labor market" in the bachelors' curriculum. Recently, the need for such disciplines [4-6] and the experience of their implementation [7] have been actively discussed in Russian professional pedagogy.

A workbook as one of the means increasing educational motivation, individualizing the learning process, and helping establish the subjectivity of a student has long been used in school and secondary vocational education.

Russian researchers emphasize the effectiveness of its use in higher professional training [8, 9, 10, 11, 12]. Foreign practice of using workbooks as a didactic and diagnostic training tool is aimed at developing and implementing electronic interactive workbooks in disciplines that meet the level of development of information and communication technologies [13, 14, 15]. The advantage of electronic interactive workbooks is that they activate and organize the work of students, allow them to maintain feedback with teachers.

A workbook is a teaching tool that has a special didactic apparatus that promotes the independent work of students mastering the discipline within and beyond the classroom to obtain and / or consolidate the theoretical material and develop required practical skills.

There are three main groups of principles that must be considered when developing a student's workbook:

- selection, presentation and structuring of the content (scientific nature, connection between theory and practice, subjectivity, accessibility, systematicity, variability);

- orientation on a personality (individualization, valuesemantic orientation, strength and effectiveness of education results, inclusion in personally significant activities, personal goal-setting, choice of an individual educational trajectory, learning productivity);

- interaction of students with the content of education, the teacher and the student (pedagogical management and independence, consciousness and activity, cooperation, positive motivation, educational reflection) [8].

Despite the fact that the compositional structure of a workbook depends on the specifics of the discipline and author's intentions, this type of study guide must meet the following mandatory requirements:

- to have an introductory part explaining the purpose of the workbook, the system of symbols used and motivating for independent work;

- to offer various types of tasks, differing by the level and nature of cognitive activities. The content and subject-specific skills should be coordinated;

- to offer educational illustrative materials;

- to include a series of control questions and / or test tasks that allow students to systematize knowledge; a list of basic and additional literature, electronic resources for completing tasks.

\section{Results and discussions}

Being a practice-oriented, the discipline "Adaptation in the labor market" is aimed at forming ideas about the initiative behavior of graduates in the modern labor market: to be able to collect and interpret information when looking for a job; to assess resources, emotional states and manage them; to have communication skills; to be able to work in a team, plan and track results of their professional activities [16].

The course "Adaptation in the labor market" is the integration of knowledge from the fields of psychology, economics, law, management, sociology in close connection with professional university training and the requirements of the modern labor market. It includes six sections:

1. Fundamentals of professional work.

2. Labor market: general characteristics.

3. Technology for effective employment.

4. Adaptation in the workplace.

5. Career as a strategy for working life.

6. Own business.

Based on the above principles and requirements, the author has developed and tested a workbook on the subject "Adaptation in the labor market" for undergraduate students [17].

The purpose of the workbook "Adaptation in the labor market" is to update and develop the adaptive potential in professional self-determination of bachelor students based on generalized theoretical knowledge about the labor market.

The following tasks were set:

- to create conditions for the development of professional and personal potential of students;

- to strengthen the confidence of graduates in their professional and personal abilities;

- to form an active behavior in the labor market and a positive attitude to the employment process;

-to help build and implement a professional career plan;

- to develop skills of an effective job search;

- to contribute to the development of business communication skills and self-presentation.

The workbook, in addition to these six topics of the course, includes a preface, which contains a general idea of the textbook and work with it, and several appendices.

The topics are learned through reproductive, reconstructive and creative tasks.

The reproductive tasks allow teachers to evaluate both knowledge of materials and an ability to use special terms. There are tasks for testing theoretical knowledge aimed to master basic concepts and approaches.

The reconstructive tasks contribute to the identification and assessment of the ability to synthesize, analyze, and generalize factual and theoretical materials and formulate specific conclusions, identify causal relationships: tasks for analyzing the situation in the labor market, professional and career competencies; psychological testing of personal and professional selfdetermination.

The creative tasks can assess an ability to integrate knowledge related to various fields, and express own 
points of view. These are individual and collective tasks aimed at improving research skills.

Each task belongs to one of three difficulty levels:

Level I - compulsory tasks (to get a "satisfactory" mark).

Level II - tasks for students who want to get a "good" or "excellent" mark.

Level III - creative tasks aimed to increase the rating.

Each topic ends with test tasks and questions for selfcontrol aimed at determining the degree of assimilation of theoretical material and a list of literature.

The students working with the workbook "Adaptation in the labor market"

- can deal with various sources of information: find sources, analyze and systematize information which is required to complete the task;

- do not need teacher's advice (there is a system of symbols, links to sources);

- draw up plans, structural and logical schemes, and fill out tables;

- psychological tests supported by explanatory applications and requiring a mandatory conclusion about the results obtained, allow students to develop personal and professional qualities, find ways to compensate for weaknesses found in personal and professional selfcharacterization, as well as adjust and build future educational and career routes.

The workbook can be effectively used as part of an independent extracurricular, in lectures (when drawing up structural and logical schemes, filling out tables and dictionaries for discipline sections), practical classes (discussion of the results of independent work on the topics, discussions, business games, etc.).

As a result, the workbook "Adaptation in the labor market" is a system of theoretical materials analyzed and systematized by students which focuses on employment issues, and a individual socio-psychological portrait, which allows for professional self-determination.

\section{Conclusion}

The introduction of the discipline "Adaptation in the labor market" in university training is a necessary measure in the framework of modernization of education aimed at developing students' competitiveness and developing their competitive ability in the labor market. Most of the time in mastering the discipline is devoted to independent extracurricular work of students, which can be evaluated by a workbook developed by one of the authors.

The use of the workbook developed by the authors to manage students' independent work and assess the level of development of competencies has the following advantages:

for the student:

- of the work mode for studying the discipline;

- building an individual educational route;

- reflection of the process and the result of educational activities;

- establishing optimal feedback with a teacher;

- motivation for self-development and self-learning;

for the teacher:
- effective management of student's independent work;

- improvement of teaching methods due to the need to search for and develop new multilevel tasks;

- reflection of professional activity.

Thus, the workbook used in training bachelor students helps organize productive independent activities of students mastering the discipline, contributes to the formation of competencies, i.e. satisfies the requirements for modern educational facilities, makes it possible to create individual educational routes, contributes to the subjectivity, increases the effectiveness of the educational process.

\section{References}

1. V. A. Degtyarev. On the issue of competence, mobility and competitiveness. Pedagogical education in Russia. 1. 112-118. (2014).

2. S. D. Reznik, M. V. Chernigovskaya, A. A. Cocilova. Competitive orientation and competitiveness of University graduates: experience, prospects of scientific research. Problems of modern economy. 3 (47). 399-402. (2013).

3. Employers don't understand generation Y: research Materials. Retrieved from: http://www.superjob.ru/research/articles/111816/rabo todateli-ne-ponimayut-pokolenie-y/ (2019).

4. E. F. Zeer. Transprofessional as a predictor of adaptation to the professional future of the individual. Innovations in professional and professional pedagogical education. 375-378. (Yekaterinburg: Russian State Vocational Pedagogical University, 2018)

5. I. V. Virina. Formation and development of competitiveness of young specialists in the labor market. (Moscow, 2007)

6. N. I. Donchenko. Problems of employment and practical assistance to graduates of higher educational institutions in social and professional adaptation in the labor market. Bulletin of Irkutsk State Technical University. 3 (43). 200-203. (2010)

7. O. L. Karachkina. Formation of professional competence of graduates of the agricultural College. Bulletin of Chita State University. 5 (50). 29-35. (2008)

8. L. A Bordonskaya, G. I. Golobokova. Workbook of university student as a Multifunctional Didactic Means. Scientific notes of the Trans-Baikal State University. Series of professional education, learning theory and methodic 6 (53). 51-66. (2013)

9. B. N Shchetkin. Workbook as one of the effective means of organization of independent work of students. International journal of experimental education. 1. 89-90. (2015)

10.E. N. Larina. Workbook as a means of forming the competencies of the future specialist. Scientific and methodical electronic journal «Concept». 15. 10611065. (2016) 
11.V. S Elagina, S. S. Khayrulin. Modern problems of science and education. Workbook as means of the organization of independent work of foreign cadets of Military Higher Education Institution. 3. Retrieved from: https://scienceeducation.ru/en/article/view?id=28763

12. T. V. Grebenshchikova, Yu. A. Lapteva, V. S. Umnov. Workbook discipline as a means of improving the efficiency of independent work of the student. News of Volgograd State Pedagogical University 2 (115). 6973. (2017)

13.S. J. Portier, H. J. H. Hermans, M. M. A. Valcke, H. M. J. van den Bosch. An electronic workbook to study statistics: Design and evaluation. Distance Education 18 (1). 59-75. (1997)

14.Jesus H. Trespalacios, Manuel A. Perez-Quinones Proceedings - Frontiers in Education Conference.
Teaching functions to pre-calculus students: an electronic-workbook. 2. 12d5-19 - 12d5-24. (1999)

15.C. J. Hollins Martin, E. Forrest, L. Wylie, C. R. Martin An evaluative survey to assess the effectiveness of using an interactive workbook to deliver bereavement education to undergraduate student midwives, Martin. Midwifery 30. Issue 8. 942-948. (2014)

16.M. V Shalaeva, V. A. Shalaev. The educational discipline "Adaptation to the labor market» in the system of university training of competitive specialist. Modern problems of science and education. Retrieved from: http://www.scienceeducation.ru/article/view?id=28578 (2019)

17.M. V. Shalaeva. Adaptation in the labor market. Workbook: a study guide. (Tyumen: Industrial University of Tyumen, 2016) 